\title{
Is Not Doing the Washing Up Like Draft Dodging? The Military Model for Resisting a Gender Based Labour Division
}

\section{SANDRINE BERGÈS}

ABSTRACT I will examine a version of Bubeck's and Robeyns' proposals for 'care duty' which looks at the ways in which care work is analogous to defence work, and what the implications are for the best models in terms both of distributive justice and serving the common good. My own analysis will differ from Bubeck's and Robeyns' in two respects. First I will apply their arguments to all aspects of care including housework. This will mean making a case for housework counting as a form of care work as it is not usually regarded as such, and in particular, would probably be excluded from Robeyns' own account as she follows Bubeck's earlier characterisation of care as involving face-to-face interaction. Secondly, I will explore various ways in which care, and especially housework, could and has been distributed by appealing to a number of military models, concluding that the best gender-just distribution of care requires a style of care experience modelled on universal military service. I will consider a number of objections to my view before concluding that not doing one's share of the housework could indeed come to be regarded as not doing one's duty as a citizen.

Care work, though deemed necessary by all, is both gendered and undervalued — and because it is undervalued, also under-compensated. That is, a vast majority of care work is performed by women, and it is either performed for free, by women looking after relatives at home, or for very little compensation. This form of gender injustice has been tied to women not being regarded as full citizens and in particular their relative absence from political life. ${ }^{1}$ In a short paper, Ingrid Robeyns proposes the following solution to the problem of gendered-ness and under-valuation of care-work: that there should be a universal duty to care, enforced by a compulsory care experience program for all citizens.

Under this proposal, all citizens should, upon reaching a certain age (say, the age of advanced adolescence or adulthood), spend some time caring for those who are in need of care: either small children, the disabled, vulnerable elderly, or the ill. By imposing this as a moral and political duty on all citizens, one would make sure that all adults have had, at the start of their adult life, a significant experience of actually performing care work. ${ }^{2}$

Though she does not go into her proposed solution in much detail, ${ }^{3}$ I find it a highly thought-provoking proposal, and one which bears investigating further. An important consequence of her proposal is that such a scheme would provide training for all to do care work so that care work would no longer be the prerogative of women, and that 
everyone would not only be competent to do it but also understand its value for humanity and the difficulties and hardships inherent in caring. In other words, it would lead to better distribution and increasing awareness of the value of care - the two problems Robeyns set out to solve.

In describing the problem and the solution, Robeyns shows that valuation is especially a matter of education in her model: people don't value care work because they don't know how hard it is, or how much it matters:

Thus, by putting all citizens in a situation in which they learn to care, they will better appreciate what care work really entails, which would make them less casual about assuming that those who do the work have an easy time, or that this is work that should not be decently rewarded, since it would amount to merely a hobby or unskilled labour. [. . .] if all men and women have an experience of care work before embarking parenthood, they will make a better informed decision on how to divide up the paid work and care work in their families. ${ }^{4}$

In this article, I wish to examine two particular aspects of Robeyns' proposal; one: the place of housework in such reform, and two: the value of using a military model (mentioned by Bubeck but not Robeyns) to understand the proposal. First, I will make a case for seeing housework as a form of care work. It is not usually regarded as such, and in particular, would probably be excluded from Robeyns' own account as she follows Bubeck's earlier characterisation of care as involving face-to-face interaction. ${ }^{5}$ I will argue, in particular, that knowing how to do housework and being prepared to do it when there are children in the house should be considered a public good, therefore one towards which it is reasonable to except that that society as a whole should contribute. Secondly, I will explore various ways in which care, and especially housework, could and has been distributed by appealing to a number of military models, concluding that the best gender-just distribution of care - i.e. one in which the burdens and rewards of care work are distributed more or less equally across genders — will be greatly facilitated by a style of care experience - including housework - modelled on universal military service.

\section{Why We Should Care About Household Chores}

In Robeyns' paper, 'care' is taken to means something specific, i.e. face-to-face interaction, helping those who cannot see to their own needs, young children, the sick, the disabled, the elderly infirm. Housework, in that sense, or food preparation is not really care work: it is work that enables care, but needn't be directed at a particular individual, and isn't always tied to others' needs specifically. For instance, a man cooking a fancy meal for his wife's birthday is not performing care work in the sense that feeding an elderly person who cannot hold her own spoon is. Making sure the family home is spotless as a matter of pride and comfort, rather than because a member of one's family is allergic to dust is again not care work, in the sense intended by Robeyns. But I here I want to argue that such work is in fact a form of care work.

Diemut Bubeck, whose definition of care Robeyns is adopting, argues that the essential feature of care is that the carer is working to meet the needs of someone who cannot meet their own needs. Bubeck seems to be right that if caring means doing something for 
someone they cannot do themselves, then cooking one's husband dinner just because traditional gender roles require it is not care work, but providing a service. ${ }^{6}$

Under Bubeck's definition care work does not require any particular emotional involvement with the caree, such that a school cook slopping food onto a child's plate at infant or primary school may well be regarded as caring. ${ }^{7}$ On the other hand, Bubeck says, care does require face-to-face interaction so that the person who serves the food to the children is a carer, but not the person who cleans the dishes or makes sure the room where the children eat is clean and pleasant. This presumably is meant to exclude the work of those involved in the production or distribution of goods that help fulfil the needs of those who cannot meet their own - such as nappy manufacturers. But in the case of work that is done directly for the caree, in the caree's own environment (home, school, hospital) it seems like a somewhat arbitrary distinction, which does not follow from the central definition. Both cook and cleaner help meet the needs of the children in their immediate environment.

There is much room for discussion about individual cases as to whether they should be described as care work, or service work, but there is one very problematic area of work that does not fall into the category of care if we follow Bubeck's definition. If care is understood as face-to-face experience and seeing to the needs of those who are not capable of looking after themselves, i.e. infants, young children, the sick, disabled and the infirm elderly, then what is not included is the general upkeep necessary for running a family home, cleaning, laundry, cooking, shopping, paying bills, etc. jobs that generally women end up doing whether they work outside the home or not, and which are neither valued nor fairly distributed. I believe that because a strong case can be made for describing these activities as care work, in the sense that they help meet the needs of those who cannot meet their own, we should abandon Bubeck's further claim that work is only care work when it is face to face.

Seeing housework as service, rather than care, makes for rather unstable conceptualisation of the actual work involved in both. The case for this is perhaps more striking when we look at the work of stay-at-home parents who care for infants and keep the house clean at the same time. Although there are cases of parents who choose to stay home with a baby and employ the services of a professional cleaner, the boundaries between the two sorts of work will necessarily be blurred. Who will be in charge of sterilising the bottles, or of making sure the baby's clothes are washed in special soap, or preparing fruit and vegetable purees to freeze for when the baby moves on to solids? It's not unlikely that the parent will regard these tasks as part of their caring duties, rather than those of the cleaner. They do not involve face-to-face interaction but they are clearly central to the baby's wellbeing and tasks that a caring parent will want to ensure are done properly (as opposed, perhaps, to making sure the windows are well cleaned or the sheets neatly folded). But the blurring of the boundaries does not stop here. A parent will probably also care that their children are brought up in a hygienic environment where they will be less likely to pick up germs, and even more so if they suffer from allergies. They will care that they are fed a healthy and varied diet, and that their meals are served at regular times, in a social environment if possible (i.e. at table, rather than in front of the TV) so that they can at the same time learn how to interact politely with each other. Some of this work can, of course, be outsourced, and if it is, may be more properly termed 'service' but it is unclear that when it is performed by a parent, it is not simply part of caring. 
One objection to portraying housework as care work is that at least some aspects of it seem to be a matter of choice rather than necessity. No one - unless there are medical reasons for it - needs a perfectly clean home. And certainly no one needs a beautiful one. Some standards of housekeeping are as self-imposed as they are unnecessary, and one may not want to fight the cause of a Martha Stewart disciple on the grounds that the work he or she performs is more a sort of vanity than desire to help those who live in the home.

Despite the fact that some forms of extreme housework may be more properly regarded as vanity than care work it is nonetheless unfair to dismiss those who feel their partners' standards of cleanliness to be too low as having domestic goddess aspirations. The family home has a distinct role to play in life, and although it need not be a shrine of style and cleanliness, those who have a home in which they feel confortable are probably better equipped to tackle the outside world. Several writers have argued that the home is a model for how we fit into society, a place where we can take on the habits and develop the character traits that will make us good citizens (Mary Wollstonecraft, Iris Marion Young, Nel Noddings - to name but a few). ${ }^{8}$ Moreover, looking after a home is never just about keeping it looking nice and comfortable. It's also about keeping oneself and one's family fed, which means shopping for food and cooking it, keeping them clothed - which means washing, drying, ironing, repairing — looking after the tools that we need to carry out these things, i.e. washing up, cleaning the fridge, the stove, the washing machine, keeping things in good repair.

Of course there are shortcuts for most of these tasks — one can survive on junk food eaten out of the packet, ready-meals heated up in the microwave and take-outs. Clothes don't have to be ironed, and someone can do a trip to the launderette once a week. In fact, many people who don't have the time or money to see to the details of housework do just that, which shows that one can bring up a family without doing much housework. ${ }^{9}$ In the same way, the work of childcare can be reduced to offering a ready-made meal to a child sitting in front of a television, or letting children prepare their own breakfasts and school bags as soon as they're able, leaving babies to cry, changing and bathing them little, etc. But, none of these are childcare choices that people would make if they actually had a choice; they represent compromises with the health and wellbeing of those we care most about. And this is also mostly true of the housework options I described - most people would prefer to live in a well-ordered home and occasionally enjoy a home-cooked meal.

Among people who can afford to choose, many tend not to go for the minimalist option. Instead, they hire someone else to clean their houses for them, and to look after their children after school. But these workers are in great majority women, and very often, poorer women who have had fewer educational opportunities — in particular, they are often from immigrant backgrounds. ${ }^{10}$ So clearly, hiring a cleaner or child-minder is not a solution to the problem of gender injustice in labour division. ${ }^{11}$

\section{Is Housework a Public Good?}

One thing that Robeyns does not explicitly note, and that Bubeck does without much discussion, but which is nonetheless striking and that I want to take up here, is the parallel between the proposal they make for universal care experience on the one hand 
and compulsory military service as a solution to keeping up an army ready to defend the nation on the other. Before I go into this in any depth, let me note that it is at least arguable that care work is both more important and intrinsically valuable than military work. But this is not something I wish to discuss here and everything I have to say is perfectly compatible with an anti-militarist perspective - or not. From the perspective of the argument I am about to deploy, it is enough to say that many people in the past and present, have seen the military as an insurmountable necessity, one without which, none of us would flourish, or even survive. Being a trained soldier was and is perceived by the majority of citizens as a job that must be done, that it requires number of people commensurate with the needs of the country, and that not enough people would choose to do voluntarily. It follows that a system must be in place that will determine who will be drafted and how. This has always struck heads of states as a problem that needed to be solved in the best, most efficient, and sometimes fairest way.

The parallels between the problems themselves should be clear by now: children need to be cared for, food needs to be prepared, houses need to be cleaned, clothes need to be washed, just as much as a country needs protecting from foreign enemies. It's not a job that every one is able or willing to do, but it must be done. Nor, especially, is it a job - or a set of jobs - that everyone who has a home or a family knows how to do for themselves. The default until now has been in great part to let families devise their own solutions, and within that model the default has been for women to do it all, or, if they could not and could afford help, to pay another, less well-off woman to do it. This would be tantamount to a state not having an army, but relying on individual families to protect their homes however they could. Having an army is regarded as more efficient and profitable: an army can present a threat, as well as defend, and it can put a nation at an advantage in international negotiations, in a way that having householders with guns does not.

One objection to my argument which I must address before going deeper into the analogy is this: whereas it is clear that care work is a public good in the sense that military service is suppose to be, doubts might be raised as to whether the same thing can be said of housework. Working in a retirement home, a nursery, a therapy centre for the disabled contributes to the public good - anybody is in a position to benefit from this work, either in person, or through someone they care about. It is even arguable that care is a public good in the stronger sense that the benefits which carers collectively produce are benefits that no one can exclude themselves from: at some point in one's life being cared for might become unavoidable in a way that is unpredictable so that if we did not contribute to care work, then we will be free riders. ${ }^{12}$ Nor can we avoid becoming free riders by writing living wills which preclude our ever becoming dependent on a carer: whether or not we need care during our adult life, we all received it as infants and for some part at least of our childhood (hopefully). If we had not, we would not be alive. So we have already benefitted from the work of carers.

So care in general is a public good, but can the same be said about housework? Whether my carpet is vacuumed affects only my family, and any guests I choose to have and who choose to come to my house. If I pay someone to clean my home, then I do so because I choose to have a pleasant home and don't want to do it myself, and in no way am I performing a public service. Similarly, if I choose to live in a tip - provided I'm not actually spreading deadly diseases - it is not up to the public to interfere. I'll clean my curtains if I want to, but not because a social worker feels I ought to. ${ }^{13}$ 
Although there is something to be said for this objection - we don't want to have the public or the state dictating how often we do the washing up - it nonetheless overstates the case for privacy and obscures the fact that homeworkers, when they keep a tidy home, are performing part of a public service at least when there are children living in the home. This is based on the premise that children themselves are a public good, and that ensuring that they grow up in a clean and safe environment is part of what is required for their successful upbringing. In what sense are children a public good? Serena Olsaretti argues that they are a 'socialized good' in the sense that 'having and rearing children in the context of a scheme that redistributes the benefits of children to non-parents alike' entails that parents have claims of fairness against non-parents. ${ }^{14}$ In other words, the benefits conferred - i.e. the next generations' tax contributions - are non-avoidable given the economic system we live in.

If we accept that children are a public good in that sense - which I do for the purpose of this article - it follows that housework is a public good if it is necessary to the successful rearing of children, i.e. if the chances of bringing up healthy and capable future citizens are affected by the lack of housework activities. There is, of course, plenty of empirical research linking childhood development to the quality of the home environment. A child's successful development from early childhood to adolescence is partly determined by the physical and structural support available within the home setting, the organisation and regularity of events that take place there, the quality and quantity of stimulating objects to be found, the cleanliness and safety of the space in which the child is free to move. ${ }^{15}$ The home environment also has an immediate effect on the child's health, studies having shown that the quality of the home environment is an important predictor of childhood obesity. ${ }^{16}$

Empirical research does show that housework is instrumental in making sure that children grow up in an environment that is safe and salutary, effectively preventing the spread of disease, and in some cases, protecting the environment from destruction. This has a further ranging effect than that which can be measured empirically (i.e. health, intelligence, and economic success). The work of educating future citizens is not one that is purely intellectual or physical but also emotional. And from that perspective, housekeeping is important. Children will feel more 'nurtured' if they live in a comfortable home, where everything has its place, and where they can rely on finding things when they need them, where the bathroom is mostly clean and where smells of cooking, not rotting, emanate from the kitchen. They will find it easier to do their schoolwork if they can rely on a clean and quiet spot, if they can find their books, and writing materials, and if they know what time to expect their evening meal. They will also grow into more responsible citizens themselves if they learn early on to accept responsibilities by doing household chores and thereby participating in creating their own comfort. If bringing up children to be healthy, productive and responsible citizens is a public good, then so is housework. In other words, there is no reason to believe that the military model would be suited to understand face-to-face care work but not housework.

Does it follow from my argument that housework is only a public good if it is performed for the sake of a child's wellbeing? To some extent it does: the extreme form of housework I alluded to in the previous section, that of the disciples of Martha Stewart, is not warranted by a child's needs. It might even, in some cases, go counter to it, i.e. by restricting the space in which the child is allowed to move freely (because she might damage a pretty room) and by moving the focus from comfort to perfection in such a way 
that the home is no longer a nurturing environment, but a showroom for domestic art. If the person who is in charge of the housework is also the child's primary caregiver then extreme housework also translates into a loss of interaction between the child and her caregiver - and that will reflect on her development. On the other hand, it would be wrong to jump to the conclusion that performing housework in only valuable if it directly benefits a particular child. Keeping a house clean and confortable is an acquired skill (even if not one that is particularly difficult to acquire) which one is not likely to become proficient in (even in the non-extreme sense) without prior practice - especially when one has just become a parent. If we agree that children are a public good, that any individual below a certain age might one day become a parent, then the capacity to perform housework adequately is a public good for all. It does not mean that individuals who are not parents and who are not responsible for the care of a person who requires a clean environment should be obliged to keep their homes clean - but they should be capable of doing so.

\section{The Case for the Military Model}

In what follows I will look at three models for creating a trained army that have been used in the past, and attempt to draw parallels with what is or should be done in order to solve the child care and housework problem. The three models are 1) economic conscription model, i.e. recruiting and encouraging recruitment from poor regions where young people feel they have no better choice, 2) the Janissaries model, i.e. enslaving a class of the population, making sure they have no other loyalty but to the army commanders, and no alternative, but train them exceptionally well and reward them highly for their service; 3) the universal military service model as currently practice in Israel: make it a requirement for all citizens of a certain age to spend a determinate amount time in the military, leaving the option of alternative service for those who cannot or will not train as a soldier.

Looking at our housework and childcare practices in the light of these models will, I argue, help us see in which ways they fail or succeed as solutions, how, for instance, they are dependent on unjust traditions, or entail some distributive injustice or inequality. I will argue, following what I take to be Robeyns' and Bubeck's proposals, that a version of the third model would work best for the problem of childcare and housework labour distribution. Last I will consider some objections to that solution.

\subsection{The Economic Conscription Model}

In 2006, Plaid Cymru, a Welsh independence party, claimed that the British army was targeting schools in the poorest areas of the country, visiting them $50 \%$ more than they did schools in more affluent parts of Wales. ${ }^{17}$ Although the army does not recruit in schools, it nonetheless offers students the opportunity to find out whether they could have a career in the army, and gives them the material means of taking the further steps involved in being recruited. In the poorer parts of Wales, this would have been the closest thing to a job offer school leavers would be likely to get. Not only was the worry that this system is exploitative - the children who live in poorer areas don't typically have a very positive vision of their future (often rightly so) and in that sense, they are easy pickings, whether or not the army turns out to be a good career for them. But also, one might well 
fear that as the area is seen as a good source for recruits, and as children themselves have the expectation of the army as being their most likely future, the incentive for developing the area diminishes.

The economic conscription model described above has implications for the current housework and childcare practices of many well-off families who pay someone to clean their homes and look after their children. There are many respects in which this is a good solution. Many parents who work often do not have time to look after their homes or engage in childcare during the day. If cleaning is to get done, it will have to be done at the expense of our or our children's welfare, i.e. instead of sleep, homework, or play time. In a sense, paying somebody to clean our homes for us is (part of) a perfect solution. The same goes for childcare: having a nanny who can look after our children before and after school enables us to work regular hours (as opposed to being constrained to the almost part-time rhythm of school hours), and to go to work even when our children are home from school. A trustworthy person who will come to our home every morning before we leave for work, and stay till we get back is a god-send for many parents, enabling them to earn a living, further their career, and have a family. So what — aside from the misplaced shame some people feel at not seeing to all their family's needs themselves is wrong with that solution? ${ }^{18}$

What is wrong with the practice of employing cleaners and child-minders is not perhaps, the practice itself, but the manner in which it is usually implemented. Those we pay to clean our houses, and to pick up our kids from school are very nearly always women, and they are very nearly always from poorer parts of society, and sometimes minority groups. In some cases, cleaners and child-minders are even from a particular country, area, or village (very much as in the cases described by Plaid Cymru). Nearly always women, these professionals end up becoming child-minders or cleaners not because this is what they choose to train as, but precisely because these are professions which we typically regard as necessitating no training - any woman can do it - and these women have not had the professional or educational opportunity which would make them fit for any other job. And because cleaning and child-minding jobs are poorly paid - it seems to make no economic sense to pay the person who looks after our home and family as much as what we make going out to work - they do not have the means to improve their conditions by saving, or paying for further training.

Although paying somebody to do the work we cannot do ourselves at home seems like a good solution to the housework problem outlined in the first section, the way in which it is currently done resembles the practice of economic draft too much to be morally acceptable. We do not redress an injustice by freeing women from unjust distribution of labour if we simply redistribute their load to poorer women who are not in a position to turn down any sort of work. Instead, by doing that, we end up reinforcing sexism and class differences. In the next section I turn to an older model of military management, and argue that despite also being fundamentally unjust it is in some ways still applied to the distribution of housework and childcare.

\subsection{The fanissaries Model}

The Janissaries were the elite troops of the Ottoman Empire first created in the $14^{\text {th }}$ century, dedicated specifically to defending the Sultan and his palace. The soldiers were young Christian boys, captured at an early age and placed in Muslim families so that they 
would learn Turkish and convert to Islam. They later received intense training and as result formed an elite with its own culture and special rights. The Janissaries were slaves, and at the same time a powerful, privileged part of Ottoman society who could influence the government of the country.

Like the first model, but in a rather more extreme way - they are enslaved — the men who make up the army do not have a choice. But in exchange, they receive not just a career and a means of supporting themselves (which they may or may not have had otherwise) but a superior standing in society, a high education, a dedicated culture (including religion, music) and political power.

There is no contradiction in the thought that a group of people will be both enslaved and have a superior standing in society. Wollstonecraft describes something very similar when she talks of the condition of rich, idle women, and the way they are made to forget that they have no real authority:

Confined in cages like the feathered race, they have nothing to do but to plume themselves, and stalk with mock majesty from perch to perch. It is true that they are provided with food and raiment, for which they neither toil nor spin; but health, liberty and virtue are given in exchange. ${ }^{19}$

Wollstonecraft's queens in gilded cages resemble the Janissaries' in that they too are given much honour, riches and apparent respect but at the expense of liberty, to the extent that they may not notice that they are not in fact free: for who would not choose to be treated like a queen? Women who stay at home to care for house and children are in sense prisoners of their cages. Their participation in public life - both economically and politically, is severely restricted - especially if they have young children, their schedule will not allow them to do much more than occasionally catch up with the news, perhaps vote, but not run for office. On the other hand, a queenly bird shining its feathers does not belong to the same category as a wife and mother, cleaning, cooking, changing nappies. But there are nonetheless some features that both have in common, and they centre on the concept of gatekeeping.

Briefly, maternal gatekeeping is a collection of beliefs and behaviors that ultimately inhibit a collaborative effort between men and women in family work by limiting men's opportunities for learning and growing through caring for home and children. ${ }^{20}$

That is, men who might share in the household chores and child-care are put off doing so by women who tell them that they are not doing it properly, who arrange schedules and routines in a way that makes it harder for their partner to participate, thereby ensuring that they alone are able to do the tasks. Of course, not all men are in this situation and some refuse to participate despite repeated requests from their partners. But, the gatekeeping phenomenon is real, nonetheless, and the Allen and Hawkins note that it is very often mothers who engage in gatekeeping as a consequence of social constructions of gender roles, and in particular, the predominance of cultural ideas of mothers as being naturally better fitted to care for children and clean houses. If one is brought up with the idea that one has special abilities, or gifts, that give one a superior standing in the family, then it will be harder to relinquish being in charge of the activities in which these abilities are typically exercised. Being a mother, being a woman, is understood as being the repository of the innate skills, which are absolutely necessary for 
ensuring that children flourish, and that the home is a safe and nurturing place for them. And this, rather than expensive clothes and jewellery, is what keeps some women believing that they are queens, that they are privileged, rather than forced into a position that no one else really wants.

The Janissaries model is essentially slavery disguised as privilege. Similarly, in many contexts and cultures, being a stay-at-home mother involves a relation of domination or dependence, notwithstanding the appearance of privilege and influence that goes with it. A woman who stays at home to look after house and children, if she is financially dependent on her partner, also depends on him for the roof over her head, and the meals that she and her children eat. In other words, refusing to comply may lead to her and her children no longer having the means to survive - at least temporarily. Such dependence, even if it does not make a slave out of woman, affects her status as a free citizen in that her choices are determined in part by the goodwill of a husband who provides for her materially. As Wollstonecraft put it:

But to render her really virtuous and useful [a wife and mother] must not, if she discharges her civil duties, want individually the protection of civil laws, she must not be dependent on her husband's bounty for her subsistence during his life, or support after his death - for how can a being be generous who has nothing of its own? ${ }^{21}$

In the next section, I will consider a model that instead of frustrating the citizenship of those who look after children, or clean houses, and without taking advantage of the desperate economic situation of some, makes a citizen's virtue out of doing one's share of the housework and childcare.

\subsection{The Universal Military Service Model}

Whereas compulsory military service is not uncommon, Israel is the only country in which conscription of women as well as men is compulsory. Young people of both sexes serve in the defence forces for a period of 18 to 36 months. Those who are not willing to serve in the army may apply for alternative service which is either care work or administration.

This is the closest to what Ingrid Robeyns proposes. ${ }^{22}$ In her model, every citizen gets to take part, for an extended but temporary period of time in their early adulthood, in what is currently considered alternative service - that is, working with infants, the elderly, the disabled, or the sick. And this service is to be valued as highly as military service is - whereas currently in many countries that do have compulsory military service, or those who did until recently, alternative service is or was regarded as less valuable so that as a disincentive, those who opt out of the military are required to serve longer.

The universal service model does not, if we follow Robeyns' view, directly answer the housework and childcare distribution problem. Serving as a carer will mean working in a nursery, a nursing home, a hospital, or a special needs institute, but not, probably, in a private home. So one thing it will not do on Robeyns' account, is provide free or cheap labourers for working parents. But what it will do is provide universal training, so that gatekeeping is no longer a consideration. Being able to look after a baby, from being women's birth-right, will hopefully come to be regarded as a skill that is acquired 
through training. Similarly, cleaning, cooking, looking after the sick and the elderly, will all be regarded as valuable skills that citizens are supposed to acquire upon coming of age. As well as breaking down gatekeeping, this will have the following benefits. First, the pool of workers will be expanded and diversified. From being a job that the uneducated and the poor do, being a house worker will be something that all citizens are qualified for. A service completion certificate will mean that a student in search of part-time work, for instance, will be a trustworthy child-minder or cleaner. Secondly, men will have received the same training in household duties as women and will therefore be able to perform the same tasks, without having to make the extra effort of learning from their wives how to wield an iron or vacuum cleaner. Nor will women be in a position to tell their husbands that they are not doing something properly — knowing how to cook, clean, or look after children will no longer be regarded as their prerogative, but as the prerogative of the citizen, male or female.

Robeyns considers the following objection to her own proposal: how about people who don't want to do face-to-face work, people who are not suited to care work or who do not think they are? Just as those who do not want to train as soldiers are sometimes offered alternative service, people whose personality make them unsuited to caring for children, the sick, disabled, or elderly ought, it seems to have an alternative option. Robeyns' first reply is that these people ought to receive training in how to become carers, so that they may learn to modulate the personality traits that make them appear unsuited to it. But this can only be part of the solution: some people simply don't want, for whatever reason, to spend time face-to-face with those who are vulnerable and need help. But whereas this may be a problem for a model that considers care to be always and only face-to-face work, I proposed, early on, that this wasn't necessarily the model I had in mind. Looking after those who cannot look after themselves, making sure that a family is able to flourish involve a large quantity of work that is not face-to-face, such as cooking, cleaning and even planning. Putting time and effort into organising the schedule of activities for a nursery, or planning and cooking healthy and tasty meals for a nursing home, being responsible for the laundry in a hospital, coordinating therapy and leisure activities in a special needs institution may not require much face-to-face interaction, but they are a part of caring, just as much as changing nappies, serving food, or performing a therapeutic activity.

\section{How Will It Work?}

In this final section, I will consider a number of ways in which the universal care duty service will alleviate the work of carers and houseworkers, helping achieve a more gender-just distribution of care work, while addressing the objection that such a service would be unduly coercive.

One reason why many democratic states prefer to have a professional rather than a conscripted army is the sense that forcing young people to join the army for one or two years after they finish school or university is unacceptably coercive. Even if we accept a thicker concept of citizenship, which emphasises citizen's duties as well as rights, and makes participation a virtue, it is still a very large commitment to demand of young people at a time when they are still only citizens in training, that is, they have not yet had the chance to fully develop their capacity for participation, and at a time when they are just taking their first steps into independent adult life. 
One possible reply to this problem is to suggest that instead of conscripting school leavers into care service, the service could be built into schooling. This would take the form of care modules or summer placements or both. Indeed, in several countries, home economics is part of the curriculum and high school children are taught how to plan cheap and healthy meals, how to care for infants, etc. Clearly, however, the impact of such programs - though it is conceivable that their existence is responsible for whatever progress has already been made in the distribution of housework - is not sufficient. And it is arguable that restricting care education to schools will not be sufficient, as no transition is made into the adult or 'real' world. However, the idea that care education and service should start at school suggests that it need not be restricted to one particular period in life. Adult citizens could choose to spread their care duties over several years, either by doing care work on a weekly basis, or spending a month each year working for a caring organisation. This would both normalise care duties and make it less of an imposition on young citizens. But this would also necessitate certain reforms in the labour market. Employers would need to make space for workers to fit in their care duties, in whichever way they saw fit - early finishes, days off, an extra month off in the summer.

The regulation of employment conditions would thus be a great part of the proposed reform, enabling the building of care duty in the employment terms for each job, such that the norm is that each employee - male or female - will have care duties of some sort, at most points in their career - whether it is performing their citizen duties, doing their share of the housework, bringing up children, looking after special needs children, sick or elderly relatives. If everyone is expected to care, employers must revise certain habits - such as compulsory late finishes, or early starts, and certain gendered expectation of what a dedicated worker will be like. This is not to say that employers must compromise on the quality of the work performed by their employees: there is, as far as I am aware, no research suggesting that workers who have to go home to pick up children, or otherwise have to manage their time more carefully, in order to fit in care duties, perform their professional duties less well than those who don't. As there is plenty of evidence, on the other hand, that such people are paid less, and less likely to be promoted, it is clear that what needs changing are attitudes and expectations, rather than standards of professionalism and productivity. Robeyns' proposal is certainly part of the solution, but it will necessitate a deeper reworking of social expectations of gender roles, professionalism and time-management.

One immediate benefit of such a scheme is that more carers would be available to help parents. If a citizen chooses to work one day a month over a period of ten years as a relief carer for disabled children, for instance, they might become paired off with a family who desperately needs someone they can trust and rely on over a period of years.

Robeyns' proposal for universal care duty shows that what is needed to make care valued by all, is to teach every citizen what is involved in caring, and help them become confident carers. Teaching everybody to do care work destroys the myth that only women can do the washing up properly, change nappies or get up in the night to calm a baby. It becomes work that requires training, and therefore work that calls for compensation as well as recognition. In other words, it solves both problems that Robeyns opened with: that of unequal distribution of care work, and that of its undervaluation - at least in so far as every body becomes aware of how difficult and unrewarding it sometimes is to look after home and babies. I have argued here both that this program should take into 
account a broader definition of care, one that includes housework, and that there are good reasons why such a duty should be implemented along the lines of compulsory military service, but one that is flexibly arranged over a citizen's lifespan rather than enforced during early adulthood. ${ }^{23}$

Sandrine Bergès, Department of Philosophy, FA Building, Bilkent University, Bilkent, Ankara 06800,Turkey.sandrineberges@gmail.com

\section{NOTES}

1 See Eva F. Kittay, Love's Labour (London: Routledge, 1999), p. 131, and Sandrine Bergès 'Is motherhood compatible with political participation: Sophie de Grouchy's care-based republicanism', Ethical Theory and Moral Practice 18 (2015): 47-60.

2 Ingrid Robeyns, 'A universal duty to care' in A. Gosseries (ed.) Arguing about fustice: Essays for Philippe van Parijs (Louvain: Presses Universitaires de Louvain, 2011), pp. 283-290 at p. 288.

3 Diemut Bubeck, 'A feminist approach to citizenship' in O. Hufton and Y. Kravaritou (eds) Gender and the Use of Time (The Hague: Kluwer Academic Publishers, 1999) also makes this proposal in the concluding section of a paper on feminist citizenship. I will discuss aspects of her proposal that are not covered by Robeyns.

4 Robeyns op cit., p. 288.

5 Diemut Bubeck, Care, Gender and Fustice (Oxford: Oxford University Press, 1995).

6 Ibid., p. 133. See also Virginia Held, The Ethics of Care, Personal, Political and Global (New York: Oxford University Press, 2006), p. 32, for a discussion of Bubeck's views.

7 Bubeck 1995, pp. 129-133.

8 Mary Wollstonecraft, A Vindication of the Rights of Woman (Oxford: Oxford University Press, 1792/1993), p. 125; Iris Marion Young 'House and home: Feminist variations on a theme' in her On Female Body Experience: 'Throwing Like a Girl' and Other Essays (Oxford: Oxford University Press, 2005), pp. 123-154, at p. 151; Nel Noddings, Starting at Home (Berkeley, CA: University of California Press, 2002), p. 5.

9 Linda Tirado, 'This is why poor people's bad decisions make perfect sense' Huffington Post 22 November 2013. Available at: http://www.huffingtonpost.com/linda-tirado/why-poor-peoples-bad-decisions-makeperfect-sense_b_4326233.html, accessed 29 January 2015.

10 See International Labour Office, 'Domestic workers across the world: Global and regional statistics and the extent of legal protection' (Geneva: ILO, 2013) for statistics that show clearly that the great majority of domestic workers throughout the world are both women and from poorer (often because immigrant) backgrounds.

11 One might wonder whether the 'wages for housework' model might not resolve many of the issues I have mentioned so far. Anca Gheaus in 'Basic income, gender justice and the costs of gender symmetrical lifestyles', Basic Income Studies 3,3 (2008): 1-8, has argued that a basic income would not solve the problems of gender justice, as it would be likely to reinforce historical shaped and adapted preferences reflecting more traditional gender roles. These considerations apply even more to the wages for housework proposal, as unlike the basic income, these are already based on a gendered division of labour.

12 For a strong definition of public goods see Serena Olsaretti, 'Children as public goods?' Philosophy and Public Affairs 41,3 (2013): 226-258, at p. 238.

13 See Young op. cit., p. 133.

14 Olsaretti op. cit., p. 256.

15 See Robert H. Bradley, 'HOME inventory' in L. Mayes \& M. Lewis (eds) The Cambridge Handbook of Environment in Human Development (Cambridge: Cambridge University Press, 2012), pp. 568-590, at p. 568, and Marc H. Bernstein, 'Proximal to distal environment in child development' in the same volume, pp. 15-34, at p. 24.

16 R.S. Strauss \& J. Knight, 'Influence of the home environment on the development of obesity in children' Pediatrics 103,6 (1999): e85.

17 "Army "targeting poorer schools" , BBC News, 4 December 2006. Available at:http://news.bbc.co.uk/2/hi/ uk_news/wales/6199274.stm, accessed 30 January 2015. 
18 Some might object that letting others care for one's children is bad for a number of reasons. Anca Gheaus, 'Arguments for non-parental care for children', Social Theory and Practice 37,7 (2011): 483-509, puts forward five convincing arguments why this is not the case.

19 Wollstonecraft op. cit., p.125.

20 Sarah M. Allen \& Alan J. Hawkins, 'Maternal gatekeeping: Mothers' beliefs and behaviors that inhibit greater father involvement in family work', fournal of Marriage and Family 61,1 (1999): 199-212.

21 Wollstonecraft op. cit., p. 227.

22 Bubeck (1999) does not consider the Israeli model, but claims that the duty to defend one's country 'was and still is gendered, since women are generally not called upon to fight, and are not admitted into combat even if they are admitted into the army' (pp. 424-5). For this reason she does not regard the military model as terribly helpful.

23 A great many thanks to Sophie-Grace Chappell, Anca Gheaus, Warren Malone, Andrei Pop, David Robjant, Jack Woods and Bill Wringe who commented on early versions of this paper, as well as to anonymous referees. 